PONTIFÍCIA UNIVERSIDADE CATÓLICA DO RIO DE JANEIRO

\title{
Melhorias Processuais Aplicadas à Área Fabril Farmacêutica
}

\section{William Cavalcante Prada}

Trabalho de Conclusão de Curso

Centro de CiênCIAS socials - CCS

DEPARTAMENTO DE ADMINISTRAÇÃO

Graduação em Administração de Empresas 


\section{William Cavalcante Prada}

\section{Melhorias Processuais Aplicadas à Área Fabril Farmacêutica}

Trabalho de Conclusão de Curso

Trabalho de Conclusão de Curso, apresentado ao programa de graduação em Administração da PUC-Rio como requisito parcial para a obtenção do titulo de graduação em Administração.

Orientador(a) : Sandra Regina da Rocha-Pinto 
"Papa, haceme grande que bobo me vuelvo solo."

(Jose Luis Prada) 


\section{Agradecimentos}

Muito obrigado aos meus pais por todo apoio, suporte e dedicação que ao longo desses anos permitiram que eu pudesse me dedicar e chegar neste momento, a então sonhada graduação. Muito obrigado a minha vó por estar presente e sempre saber que eu não iria me formar em agosto... de Deus. Muito obrigado ao meu avô, pois mesmo que não esteja conosco sei que ele está torcendo por mim e pela nossa família aonde quer que ele esteja.

Obrigado aos meus amigos pela por paciência, compreensão, constante vaias e pelo fato de aguentarem ficar sem minha ilustre presença, pois foram dedicadas inúmeras horas para a elaboração do trabalho.

Obrigado à minha orientadora, a professora Sandra Regina Pinto-Rocha, pelo auxílio na elaboração do trabalho.

Obrigado Vanessa, embora nunca tenha te conhecido eu sinto que já te conheço há muito tempo. Você sempre esteve presente quando eu mais precisava, me motivando a continuar no caminho certo. Obrigado Lilian por me apresentar a Vanessa. Acho que sem você, esse trabalho estaria sendo entregue talvez em um período futurístico, obrigado por sempre estar presente e por tudo, acho que não caberiam expressar minha gratidão aqui. Obrigado Aluane por extorquir meu suado salário em empadas na PUC. Embora eu tenha citado a Lili primeiro, espero que você não fique com ciúmes, pois a amizade que tenho por vocês duas é igual e imensurável. PS: Desculpa por todos os assuntos desse semestre ser sobre o TCC.

Obrigado a todos meu amigos Felipe, João, Gerude, Erik, Fernando, Vinicius, Aderbal, José, Vitor, Mateus, Maiara, Wellington, Lenine, Rodrigo e todos à quem esqueci de mencionar, vocês, juntos à mim, me ajudaram construindo esse trabalho e dedico este à vocês.

Por fim, agradeço novamente à minha família, pois sem eles nada disso seria possível, e o que eu escrever aqui nada adianta se não for grato todo dia por ter pessoas tão inspiradoras na minha vida. 


\section{Resumo}

Prada, William Cavalcante. Melhorias Processuais Aplicadas à Área Fabril Farmacêutica. Rio de Janeiro, 2016. Número de páginas 45. Trabalho de Conclusão de Curso - Departamento de Administração. Pontifícia Universidade Católica do Rio de Janeiro.

O presente trabalho consiste em estudo sobre o processo fabril de uma empresa farmacêutica, mais especificamente do segmento de saúde animal. 0 objetivo do presente estudo foi analisar o cotidiano organizacional de um processo fabril, por batelada (por demanda), sob a ótica de gestão de processos, identificar os pontos críticos e sugerir melhorias. O trabalho contou com uma pesquisa qualitativa semiestruturada com os envolvidos no processo. Os resultados das pesquisas tiveram como principal tema a consciência do processo e comunicação interna, servindo assim como base para as sugestões de melhorias processuais.

Palavras- chave

Processos; processo fabril; gestão de processos; mapeamento de processos; melhoria de processos.

\section{Abstract}

Prada, William Cavalcante. Improvementes Applied to the Farmaceutical Industry. Rio de Janeiro, 2016. Number of pages 45. Final Paper Business Administration Department. Pontifícia Universidade Católica do Rio de Janeiro.

This study is about an industrial process of a pharmaceutical company, specifically acting on the animal heath market. The main objective of the present study was to analyze the daily tasks and activities of the organization's industrial process, identifying critical areas and suggesting improvements, under the lenses of process management theories. The methodology of the study consisted in a qualitative research, carrying out a semi-structured interview with the personnel involved in the process. The results pointed out to the awareness of the process itself and the internal communication of the company, the results were used to suggest improvements to the process.

Key-words

Process; industrial process; process management; process modeling; process improvements. 


\section{Sumário}

1 O tema e o problema de estudo 1

1.1. Introdução ao tema e ao problema do estudo 1

1.2. Objetivo do estudo 3

1.3. Objetivos intermediários do estudo 3

1.4. Delimitação e foco do estudo 3

1.5. Justificativa e relevância do estudo 4

2 Referencial teórico 5

2.1. Processos 5

2.2. Melhoria contínua 8

2.3. Reengenharia de processos 9

2.4. Modelagem de processos 11

2.5. Gerenciamento de processos 12

$\begin{array}{ll}\text { 2.5.1. Gerenciando mudanças } & 13\end{array}$

3 Métodos e procedimentos de coleta e de análise de dados do estudo 17

$\begin{array}{ll}\text { 3.1. Etapas de coleta de dados } & 17\end{array}$

3.2. Fontes de informação selecionadas para coleta de dados no estudo17

3.3. Procedimentos e instrumentos de coleta de dados utilizados no $\begin{array}{ll}\text { estudo } & 18\end{array}$

3.4. Formas de tratamento e análise dos dados coletados para o estudo19 3.5. Limitações do Estudo

4 Apresentação e análise dos resultados 20

4.1. A Empresa 20

4.2. Descrição do perfil dos entrevistados 21

4.3. Descrição e análise dos resultados 21

4.3.1. Mapeamento do processo 21

4.3.2. Variáveis intervenientes 25

4.3.2.1. Consciência do processo 25 
4.3.2.2. Restrições do processo produtivo 26

4.3.2.3. Processo fabril e comunicação com o seu fornecedor 27

4.3.2.4. Melhorias processuais 29

4.3.2.5. Participação processual 30

5 Conclusões e recomendações para novos estudos 32

5.1. Sugestões e recomendações para novos estudos 34

6 Referências Bibliográficas 36

$\begin{array}{ll}\text { Anexo } 1 & 40\end{array}$

\section{Lista de figuras}

Figura 1: Mapa do Processo Fabril..........................................................22

\section{Lista de tabelas}

Tabela 1: Análise Comparativa entre as proposta de Gerenciamento de Processos com os Critérios Facilitadores de Mudança

Tabela 2: Perfil dos Entrevistados 


\section{0 tema e o problema de estudo}

\subsection{Introdução ao tema e ao problema do estudo}

Da hora que acorda até a hora de dormir, o cotidiano das pessoas passa por um conjunto de ações e tarefas no qual, muitas vezes, sem perceber as realizam de maneira automática. Demorou certo tempo para as pessoas compreenderem qual seria a melhor forma de executar as suas tarefas de modo eficiente e eficaz. Esses conjuntos de tarefas do dia a dia de cada indivíduo também compõem o fluxo de processos de uma empresa.

Para um estudante, o mau planejamento do seu período letivo pode fazer com que ele reprove uma disciplina, perdendo tempo, energia e dinheiro, assim tendo que pagar novamente os créditos para refazê-la. Já para uma empresa, o mau planejamento pode sair mais caro, tendo que reinvestir seus ativos ou até mesmo realocar seus recursos em outros departamentos para a elaboração de uma força tarefa, necessária pelas pendências do reprocesso.

O processo pode ser descrito de diversas formas. Uma das maneiras mais simples de descrever a definição de um processo seria compará-lo com uma linha produtiva de uma fábrica, seja ela de qualquer indústria. Nesta fábrica, existem atividades divididas em etapas que são executadas sequencialmente ou em paralelo, no qual, ao término dessa linha de produção (fluxo de trabalho), o produto final agregará valor ao cliente.

De acordo de De Sordi (2015), desde a Revolução Industrial, durante o século XVIII, a ideia de racionalizar tarefas e especialização da mão de obra é estudada. O que se percebe é que, desde 1776 com Adam Smith publicando seu livro Riqueza das Nações, trazendo a experiência de uma fábrica de alfinetes dividida em onze operações, passando por Frederick Winslow Taylor, em 1911, com sua obra Principles of Scientific Managment e quase junto com os processos revolucionários de produção em massa de Henry Ford, os estudos voltados à racionalização da tarefa e especialização começavam a ser disseminados internacionalmente, assim, passando a ser uma realidade de qualquer empresa competitiva. 
Esses estudos foram inseridos na Administração, onde mais tarde teve sua aplicação em empresas industriais, devido à evolução do mercado de consumo e também da implementação das tecnologias de produção. Após a Segunda Guerra Mundial, em 1945, essas empresas se tornaram imensos conglomerados cuja estrutura organizacional era funcional, onde um departamento não tinha conhecimento do outro e nem uma visão ampla do negócio (DE SORDI, 2015).

Com a reengenharia de processos e as novas tecnologias, a pressão por otimização de recursos e a falta de visão holística na Estrutura Organizacional das empresas fizeram com que elas se direcionassem a uma alternativa, a Gestão de Processos de Negócios ou Business Process Managment (BPM) (DE SORDI, 2015). A Gestão de Processos de Negócios é uma ferramenta que visa responder um novo desafio recorrente de como administrar uma empresa matricial. "Essa visão compreende todo o trabalho executado para entregar o produto ou serviço do processo, independente de quais áreas funcionais ou localizações estejam envolvidas" (BPM CBOK, 2013, p. 33). Neste sentido é possível perceber que as organizações estão se voltando para a otimização dos seus recursos e processos, ou deveriam, tornando suas boas práticas um ganho interno e agregando valor ao seu cliente final.

Neste contexto, as empresas voltadas para processos estão começando a surgir como estrutura predominante no século XXI (HAMMER, 1996), deixando de lado sua estrutura funcional, herdada desde o pós-guerra e a evolução do mercado de consumo, e dando maior ênfase nos seus processos e não em cada área envolvida em sua execução (DE SORDI, 2015). Com a mudança do foco organizacional, novas propostas são apresentadas para melhorar o processo do negócio. Alguns exemplos e consequências dessas novas práticas são a gestão de relacionamentos com os clientes ou Customer Relationship Managment (CRM) e a gestão da cadeia de fornecedores ou Supply Chain Managment (SCM).

De acordo com um estudo elaborado pela ELO Group (2013) sobre práticas adotadas em gestão de processos por empresas brasileiras, conclui-se que grande parte das delas utilizam seus processos para padronizar suas atividades e não para gerar impactos de melhoria em produtos e serviços aos seus clientes. Embora a empresa analisada seja uma multinacional, seus gestores são de nacionalidade brasileira e com formação nacional, desta forma podendo comparar e avaliar a empresa em relação à utilização de seus processos com as demais empresas brasileiras. 
Com o aumento da importância desses estudos e nas transformações estruturais das organizações é inevitável à adequação das empresas. Desta maneira, o presente trabalho se caracteriza em analisar os processos de uma empresa fabril do ramo farmacêutico, fazendo um mapeamento do ciclo fabril para responder: quais pontos críticos poderiam ser melhorados no processo fabril de uma empresa do ramo farmacêutico?

\subsection{Objetivo do estudo}

O objetivo central do estudo é identificar pontos críticos do processo fabril de uma empresa do ramo farmacêutico e a melhor maneira de gerenciá-los.

\subsection{Objetivos intermediários do estudo}

Os passos intermediários necessários para alcançar o objetivo final do estudo são os seguintes:

- Apresentar conceitos sobre processos e modelagem

- Entender a totalidade do processo fabril

- Modelar o processo fabril e ouvir seus participantes

- Identificar os pontos críticos

- Definir métricas para análise

- Sugerir melhorias

\subsection{Delimitação e foco do estudo}

Este trabalho estudará o processo fabril de uma empresa privada do ramo farmacêutico, desde as suas previsões de vendas até o escoamento do produto acabado ao depósito da empresa. Identificando e analisando melhorias aos principais pontos críticos relacionados ao processo fabril como um todo.

Vale ressaltar que não é objetivo da pesquisa desmembrar os processos internos do setor de produção, tais como: o processo de formulação e de envase, pois dada a complexidade dos processos produtivos, a melhor forma de abordá-los seria através de estudos e pesquisas complementares, enriquecendo o presente trabalho. 


\subsection{Justificativa e relevância do estudo}

O presente estudo analisará os pontos críticos do processo fabril de uma empresa privada, destacando assim como eles poderão ser melhorados e gerenciados. Este estudo tem sua importância, pois poderá ser analisado pela empresa porque implicará em melhorias diretas para a rotina produtiva, o que poderá ser replicado também para as demais unidades da empresa situadas em outras cidades.

A organização possui elementos internos que reforçam a melhoria constante de seus processos e possui também recursos para replicar esse modelo para diferentes processos estratégicos. 


\section{Referencial teórico}

\subsection{Processos}

A palavra "processo" em si pode ter vários, porém quando acondicionada a um contexto, ela acaba se categorizando e gerando um sentido, como por exemplo, no contexto químico da palavra, o processo seria um conjunto de operações sucessivas pelas quais se realiza uma operação química, farmacêutica, etc. (Dicionário Online Michaelis). Já no âmbito da Administração, processo pode ser definido por "como produzir alguma coisa" (MALONE et al., 1997, p. 9) e também por "a forma pela qual as coisas são feitas na empresa" (LIPNACK E STAMPS, 1997,p. 9). Comparando essas definições, consegue-se entender que processo é um conjunto de atividades que geram, ao seu término, um produto ou um resultado.

Os processos, dentro de uma empresa, podem ser classificados como dois tipos: processos internos, no qual possuem sua origem e término dentro da organização, e os processos externos. De acordo com Gonçalves (2000, p. 12), a primeira característica importante dos processos é a interfuncionalidade, mesmo que em sua grande maioria ocorra dentro de uma unidade funcional, os processos importantes acontecem atravessando a estrutura funciona de uma organização (GONÇALVES, 2000). "A segunda característica importante dos processos de negócio é o fato de que eles têm clientes" (DAVENPORT E SHORT, 1990, p. 12). Aonde, durante a execução do processo, envolvendo todas as áreas da empresa, acarretam em entregar um serviço ou bem ao cliente.

Trazendo esse conceito para uma Administração, consegue-se interligar o processo aos principais conceitos relacionados a sistema, no qual tem sua definição por "um conjunto de elementos interdependentes e interagentes que formam um todo organizado no sentido de alcançar um objetivo" (CHIAVENATO, 2003, p. 496). Decompondo um sistema como um todo, se observa que existe o recurso inicial (matéria prima) para se produzir, conhecido como input, no qual passa pelo processo de transformação até sair como output, ou um bem gerado da soma dessas etapas. Em um contexto fabril, o processo pode ser 
caracterizado pelo mesmo modelo apresentado, porém com um maior grau de complexidade.

Em conjunto com a temática de processos e sistema, existe a Teoria das Restrições no qual parte do pressuposto que todo sistema possui um número pequeno de fatores que limitam a eficiência do sistema como um todo (Costa Marques e Sales Cia, 1998). De acordo com Costa Marques e Sales Cia (1998), é necessário que se tenha uma visão do ciclo do processo para que seja possível identificar o gargalo e também possível identificar dois tipos de restrições em um processo: física que estaria associada diretamente com a capacidade produtiva, à logística e fornecimento de materiais; e também as não físicas, que estão ligadas à burocracia, procedimentos internos e até mesmo fatores comportamentais. Comparando à organização estudada, encontraremos alguns gargalos do processo produtivo identificados pelos colaboradores entrevistados que se enquadram nos dois tipos de restrições acima definidos.

Com a constante busca pela competitividade operacional e os avanços tecnológicos, novas tecnologias foram sendo implementadas nas organizações, onde as que teriam adquirido tais sistemas teriam uma vantagem competitiva perante as demais. $O$ funcionamento dos processos necessita ser constantemente adequado e redesenhado, a fim de sempre suprir as necessidades de eventuais situações nas quais as empresas estarão. Como forma de adequação às mudanças, por parte das empresas, a criação da área de Supply Chain Management, que integra a cadeia de suprimentos com a cadeia de distribuição, substituindo o departamento de logística, assim como os sistemas de ERP (Enterprise Resource Planning) que possibilitam, de maneira customizada, seus usuários a controlar o fluxo de processo, interligando cada área da empresa, desta forma, tornando uma cadeia de fluxos de trabalhos em apena um único e integrado fluxo de processo (GONÇALVES, 2000) foram consequências desses avanços tecnológicos.

Analisando a empresa estudada, percebe-se que ela utiliza um sistema ERP, o programa SAP, que tem como conceito base a integração das áreas funcionais da empresa, unificando todas as informações da organização numa única base de dados. Esta ferramenta faz parte de uma tecnologia chamada CIM (Computer-Integrated Manufacturing), que nada mais é do que uma rede de softwares e hardwares controlados por seus usuários no intuito de otimizar o processo fabril (POLAKOFF, 1990). Desta forma, a tecnologia consegue se destacar com a ferramenta de redesenho de processos por excelência (GONÇALVES, 1995a). De acordo com um estudo elaborado pela ELO Group 
(2013), o cenário na qual as empresas brasileiras estão, em relação aos processos é que elas estão utilizando-os apenas para padronizar as transformações que já ocorreram e não para gerar melhorias nos seus produtos e serviços oferecidos aos seus clientes.

Agora com a visão de processos "aprimorada", tendo seu enfoque na melhoria interna, padronização e clientes, surge um novo conceito que busca alinhar práticas, ao longo da organização, que assegure que elas satisfaçam e excedam todos os requisitos do cliente (BPM CBOK, 2013), sendo esse novo conceito chamo de Gerenciamento da Qualidade Total. O enfoque na qualidade começou a ganhar maior visibilidade no pós-guerra com a reconstrução da indústria japonesa. Os resultados obtidos na implementação de controle na produção foi tão positivo que o Japão se tornou o pioneiro nos processos de controle de qualidade, elaborando metodologias, tais como: 5S's, Just-in-time e o próprio TQM (FISCHI, 2012).

Desta maneira, a análise estatística e cálculo de probabilidade tem sua aplicabilidade no Controle de Processo (CEP) na área de produção, onde é utilizado este método para obter o máximo de informações possíveis com a menor quantidade de dados (CHIAVENATO, 2003), desta forma, fazendo com que durante um processo produtivo a empresa não perca ou tenha que separar produtos demais ou de menos para serem estudados, deixando de lucrar com a venda dos produtos retidos. "O controle estatístico da qualidade tem como objetivo localizar desvios, erros, defeitos ou falhas no processo produtivo, comparando o desempenho com o padrão estabelecido"' (CHIAVENATO, 2003, p. 452).

Com a nova visão de processos voltada agora para os clientes e não mais voltadas às organizações em si, acabou-se gerando a necessidade das empresas adaptarem ou redesenharem seus processos de negócios. A adoção de uma estrutura baseada nos processos significa, em geral, dar menos ênfase à estrutura funcional do negócio (DAVENPORT, 1994) e empregar outros modelos organizacionais e de negócios (GONÇALVES, 1998).

Numa outra ótica, os processos utilizam os recursos da organização para oferecer resultados objetivos aos seus clientes (HARRINGTON, 1991), onde também pode ser esboçado como um grupo de atividades realizadas, numa sequência lógica com o objetivo de produzir um bem ou serviço que tem valor para um grupo específico de clientes (HAMMER E CHAMPY, 1994). Para a Administração, o conceito de processos não é recente, porém quando se trata em dizer que o foco do negócio deve ser direcionado para agradar o cliente e 
também equilibrar o que é rentável com a empresa a fim de não quebrá-la agradando seus clientes (TENDICK, 1999). Assim sendo, mostra-se uma necessidade que este pilar das empresas seja gerenciado a redesenhado caso necessário, estando sensível à mudanças e sempre gerando valor aos seus clientes.

\subsection{Melhoria contínua}

"A melhoria contínua é uma técnica de mudança organizacional suave e contínua centrada nas atividades em grupo das pessoas. Visa à qualidade dos produtos e serviços dentro de programas a longo prazo, que privilegiam a melhoria gradual e o passo a passo por meio da intensiva colaboração e participação das pessoas" (CHIAVENATO, 2003, p. 580).

De acordo com Chiavenato (2003), em grande parte, nenhum programa de melhoria contínua tem seu resultado aprovado quando é implementado de cima para baixo, mas sim, começando com uma equipe e de baixo para cima na escala hierárquica. Esta metodologia tem como característica forte a participação dos indivíduos envolvidos no projeto ou processo, assim como uma abordagem incremental (CHIAVENATO, 2003), onde gradativamente se melhora atividades do processo para melhorar o processo como um todo.

O termo "Melhoria Contínua" tem sua origem da palavra japonesa Kaizen, onde significa boa mudança. "O Kaizen é uma filosofia de contínuo melhoramento de todos os empregados da organização, de maneira que realizem suas tarefas um pouco melhor a cada dia" (CHIAVENATO, 2003, p. 580). Fazendo uma correlação com a empresa estudada neste artigo, conseguese observar a vivência desta filosofia no dia a dia. Existe um departamento chamado de Excelência Operacional, onde junto com os colaboradores, criam-se projetos para melhorar a produção, evitar desperdícios e qualquer ideia inovadora que um colaborador possa vir a gerar. A abordagem desta técnica, não significa que ela não venha abraçada com resultados a serem alcançados, pois o Kaizen não significa somente executar suas tarefas da melhor maneira possível, mas sim executá-las da melhor maneira possível trazendo resultados para a organização, tais como: evitando retrabalho, redução de custo operacional, menor desperdício de material (CHIAVENATO, 2003). Sempre tendo como foco, agregar valor ao cliente.

Para a melhor utilização da filosofia Kaizen, os projetos de melhoria contínua não devem ser estáticos, mas sim estar em constante manutenção 
(CHIAVENATO, 2003) para suprir qualquer necessidade que a organização possa ter ao longo de suas tarefas, atividades ou processos. As ideias não precisam ser altamente elaboradas para se tornarem melhorias, mas devem ter seus resultados contínuos e constantes depois de implementados. Para que essas ideias sejam geradas, essa filosofia requer que as pessoas sejam incentivadas a pensar e tenham um olhar crítico e construtivo (CHIAVENATO, 2003). De acordo com Wellington (1999), o Kaizen é uma maneira de uma empresa pensar e agir seguindo alguns princípios, sendo eles:

- Promover aprimoramentos contínuos;

- Enfatizar os clientes;

- Reconhecer os problemas abertamente;

- Promover a discussão aberta e franca;

- Criar e incentivar equipes de trabalho;

- Gerenciar projetos por intermédio de equipes multifuncionais;

- Incentivar o relacionamento entre as pessoas;

- Desenvolver a autodisciplina;

- Comunicar e informar a todas as pessoas;

- Treinar intensamente e capacitar todas as pessoas.

Segundo Chiavenato (2003), o Kaizen foi o primeiro movimento no qual envolvia a organização toda que focava na importância das pessoas e das equipes de trabalho. O Kaizen preza pelo envolvimento de todos os colaboradores e não somente aqueles envolvidos em certa tarefa ou processo, tirando, deste modo, a responsabilidade de um único indivíduo e envolvendo todos os demais colaboradores, prática parecida com a Reengenharia de Processo, onde ela visa descentralizar os processos. Porém, a diferença entre uma metodologia e a outra é dada pelo impacto que é causado na empresa, onde a melhoria contínua tem seu enfoque gradual a longo prazo e a reengenharia de processos tem como característica ser radical e traz resultados imediatos.

\subsection{Reengenharia de processos}

"A reengenharia tem suas origens em várias abordagens organizacionais que incluem o movimento da qualidade, o gerenciamento científico, a escola sóciotécnica e a tecnologia da informação" (DAVENPORT E STODDARD, 1994, p. 31). Tanto a temática de Qualidade Total como a Reengenharia possui foco 
tanto nos processos organizacionais como em atender as reais necessidades de seus clientes.

Tendo seu enfoque em processos interfuncionais e redesenho processuais, este conceito se aproxima ao conceito da cadeia de valor de Porter (PORTER, 1989), onde atividades de apoio e atividades principais devem estar interligadas a fim de gerar uma vantagem competitiva à empresa. Segundo Valentina (1998), quando se fala sobre reengenharia é inevitável trazer à comparação com os conceitos de Taylor, de um modo que ambas as escolas possuem características similares, tais como:

- Separação entre a execução do trabalho e projeto;

- Idealização de que existe um processo ideal para qualquer tipo de trabalho;

- Medição e Controle da eficiência e eficácia dos trabalhos realizados;

- Utilização de procedimentos e/ou roteiros para o cumprimento atividades realizadas pelos trabalhadores.

As características são muito semelhantes entre as duas linhas de pensamento, porém a grande diferença seria que a visão de Taylor negligenciava a mudança do processo (redesenho) e também como as organizações, em conjunto com os seus colaboradores, possuem o fator motivacional e também no processo em si, conceitos que são abordados na reengenharia (VALENTINA, 1998). De acordo com Hammer e Champy, as organizações já estavam praticando a reengenharia de antes mesmo que o próprio Hammer a definisse (HAMMER, 1990) e mesmo sem saberem de sua real aplicabilidade processual.

A reengenharia tem como foco principal a mudança processual de seu atual processo, ou seja, realinhar o agrupamento de atividades realizadas em cada departamento da empresa. Com o realinhamento de atividades, o novo processo passa a ser mais descentralizado, gerando envolvimento interfuncional de todos os envolvidos no novo fluxo de processo e consequentemente não atrela responsabilidade a uma única pessoa, mas sim, aumenta a responsabilidade de todos os envolvidos buscando, desta forma, a melhora da qualidade e no desempenho do processo (VALENTINA, 1998).

Uma das definições de Reengenharia, no qual se consegue identificar toda sua abrangência e dimensão, seria "O redesenho radical dos processos de trabalho para atingir uma melhoria dramática no desempenho" (HAMMER E 
CHAMPY, 1993, p.37). Dessecando e analisando esta definição é possível entender os reais aspectos do conceito de Reengenharia. As palavras "radical", "dramática", "processo" e "desempenho" trazem consigo uma profundida ampla à sua definição. Radical, pois a organização deverá atuar em cima da causa raiz, identificando o problema processual e redesenha-lo, para atender a organização da melhor forma possível. Dramático, porque não se trata de ações que visão uma melhoria gradual ou contínua, mas sim ações que impulsionam o Desempenho de maneira abrupta. E por fim, a palavra processo, dando ênfase que a reengenharia tem como seu pilar central os processos organizacionais (VALENTINA, 1998).

A reengenharia traz uma melhoria radical e não apenas melhorias contínuas, sempre visando satisfazer o seu cliente e demais stakeholders. O redesenho dos processos, traz consigo diversas consequências ao ser implementado tanto nos atuais processos como cultura, práticas gerenciais e relacionamento. Uma vez adotada, poderá trazer vantagens competitivas ao negócio, através de:

- Redução do ciclo do processo e consequentemente nos custos da empresa;

- Eliminação ou Redução de atividades que não agregam valor;

- Melhoria nos serviços de atendimento ao cliente;

- Desenvolvimento de competências ao negócio.

\subsection{Modelagem de processos}

"Modelagem de processos de negócios é o conjunto de atividades envolvidas na criação de representações de processos de negócios existentes ou propostas. Pode promover uma perspectiva ponta a ponta ou uma porção dos processos primários, de suporte ou de gerenciamento" (BPM CBOK, 2013, p. 72).

A utilização da modelagem de processos tem como finalidade representar o mapa processual de uma empresa da maneira mais completa e detalhada possível. O Mapeamento pode ser elaborado em diferentes níveis de detalhamento, podendo variar de uma visão abstrata até uma visão complexa do processo. "O mapeamento de processos é uma ferramenta gerencial analítica e de comunicação que têm a intenção de ajudar a melhorar os processos existentes ou de implantar uma nova estrutura voltada para processos" (CORREIA,LEAL E ALMEIDA, 2002, p.3). Com a sua utilização, as organizações 
podem, através de análises do mapeamento, identificar pontos de redução de custo e redução de falha ao longo do ciclo do processo, além de possibilitar o melhor entendimento dos processos atuais da organização, podendo eliminar ou simplificar atividades, tarefas ou processos que necessitam de mudanças (VILLELA apud.hunt, 1996).

Conforme Kettinger et al. (1997), existem diferentes métodos de representar e construir modelos de processos. Mas segundo Biazzo (2000), para qualquer estratégia adotada, seguem-se algumas premissas básicas, tais como:

1. Definição das fronteiras e dos clientes do processo, dos principais inputs e outputs e dos atores envolvidos no fluxo de trabalho;

2. Entrevistas com os responsáveis pelas várias atividades dentro do processo e estudo dos documentos disponíveis;

3. Criação do modelo com base na informação adquirida e revisão passo a passo do modelo seguindo a lógica do ciclo de "authorreader" (onde o "reader" pode ser tanto aqueles que participam do processo como potenciais usuários do modelo).

O mapeamento de processo é visto como uma ferramenta de extrema importância para que se possa entender e dimensionar a estrutura do fluxo de trabalho, áreas envolvidas e poder de decisão. Desencadeando desta maneira avaliações que possam mensurar a eficiência e eficácia ao processo, assim como poder realinhá-lo (CORREIA, LEAL E ALMEIDA, 2002).

\subsection{Gerenciamento de processos}

Com as ferramentas e abordagens mencionadas acima, é necessário que se tenha também uma ferramenta de gestão que consiga compilar todas essas novas metodologias e gerir a nova empresa, migrando-a de uma estrutura organizacional funcional para uma matricial. Gonçalves (1997b, p.19) menciona:

"De modo geral, o futuro vai pertencer às empresas que consigam explorar o potencial da centralização das prioridades, das ações e dos recursos nos seus processos essenciais. As empresas do futuro deixarão de enxergar processos apenas na área industrial, serão organizadas em torno de seus processos não fabris essenciais e centrarão seus esforços em seus clientes."

Demonstrando que de fato as empresas não podem apenas enxergar o processo na parte operacional, mas também nas partes secundárias e de apoio, sempre tendo em mente que precisam agregar valor aos seus clientes. Assim 
sendo, o Guia BPM CBOK (2013) define que o Gerenciamento de Processos de Negócios, ou BPM - Business Process Management, é uma nova maneira de visualizar as Operações de negócios indo além das estruturas organizacionais tradicionais. Deste modo, entende-se que todas as áreas da empresa estão interligadas e não mais separadas por departamentos individuais, sempre visando entregar um produto ou serviço para seu cliente oriundo do seu processo.

O funcionamento das empresas de acordo com a lógica dos processos implica a adoção de novas maneiras de trabalhar e de gerenciar o trabalho (GONÇALVES, 1997b). Além dessa nova abordagem de se trabalhar o Guia BPM CBOK (2013, p. 52) cita que as empresas devem constantemente reavaliar seus processos e ter um comprometimento vitalício. "Envolve uma continuidade, um ciclo de feedback sem fim para assegurar que os processos de negócio estejam alinhados com a estratégia e ao foco do cliente. "Situação essa que é vivida, em partes, pela empresa estudada, onde existem ruídos no ciclo de feedback, comunicação e no gerenciamento do processo.

Desta maneira, entende-se que o Gerenciamento de Processos é uma abordagem que altera não somente o tipo de estrutura organizacional da empresa, abandonando a estrutura funcional, mas também exige uma mudança cultural, pois novos critérios, cargos, tomadas de decisões podem ser alteradas ao redesenhar, modificar ou melhorar os processos. Equipes multifuncionais, de diferentes departamentos da empresa avaliarão novos critérios e irão propor novas metas com base na eficiência do processo e não mais isolar as metas por função departamental.

\subsubsection{Gerenciando mudanças}

De acordo com Silva et al.(2009, p. 1) a importância de um gerenciamento de processos tem como entendimento:

\footnotetext{
"O Gerenciamento de Processos pode ser muito útil às empresas porque busca, por meio da melhoria contínua e horizontalização da estrutura organizacional, a eficiência e a qualidade crescente para os produtos e serviços, agregandoIhes maior valor, a fim de atender de forma mais adequada e ágil às necessidades dos clientes."
}

Com o grau de incerteza do mercado, empresas e ambientes competitivos é inevitável que as organizações encontrem maneiras de satisfazer seu cliente com um grau de excelência, sempre impondo vantagem em cima de seu 
concorrente (SILVA et at., 2009). Desta maneira, as empresas estão cada vez mais deixando suas antigas estruturas verticais e passando a aderir uma visão horizontal e integrada de todas as áreas da empresa, a fim de agilizar e tornar o processo mais eficiente, atendendo assim as necessidades de seus clientes (SILVA et al., 2009).

De acordo com Bressan (2004), as empresas que adotam esse novo modelo estrutural estão se deparando com uma barreira em fazer com que seus envolvidos estejam comprometidos e conscientes das mudanças. De forma que, ao propor os "fatores facilitadores de mudanças" ao redesenho possa reduzir as eventuais resistências que serão encontradas pelas pessoas e pela cultural organizacional, que serão afetadas no seu trabalho, sistemas que utilizam e na própria estrutura organizacional.

Para ter um Gerenciamento de Processos a empresa necessita saber que o seu processo não é o que seus colaboradores fazem, mas sim a soma das atividades executadas que geram um resultado ao cliente final. Tendo então conhecimento que o processo é a soma das atividades executadas, o gerenciamento de processos, segundo Rummler e Brache (1994), é definido por um compilado de ações, modelos e técnicas para garantir que os processoschaves sejam acompanhados e melhorados continuamente, desta forma obtendo uma visão holística e processual da empresa. Segundo Pritchard e Armistead (1999), a abordagem funcional das empresas é baseada em cada departamento executando sua tarefa isoladamente, e desta forma a empresa, como um todo, perde agilidade em seu processo e competitividade no seu segmento de mercado, aonde ocorrem variações rápidas e a constante necessidade de adaptação.

Dentro do cenário de transição, novas metodologias de desenvolvimento de implementação de gerenciamento de processos foram desenvolvidas na década de 1990, de acordo com um estudo de Silvia et al. (2009), tendo como principais autores: Adair e Muray (1996), Almeida (1993), Ballé (1997), Carr et al. (1994), Harrington (1993), MCG Qualidade (1999) e Rummler e Brache (1994). A proposta do estudo foi observar onde existe um consenso por parte dos autores, a saber: identificar as necessidades dos seus clientes, eleger a equipe de qualidade e o dono do processo, mapear o processo e estabelecer e propor metas de desempenho, além de identificar, planejar e implementar as melhorias propostas. Todos esses critérios relacionados à análise e melhoria contínua do processo. 
Por outro lado, alguns desses autores fazem abordagens singulares, tais como: Adair e Murray (1996) abordando o conhecimento do ambiente externo e Rummler e Brache (1994) citando o desenvolvimento do "mapa de relacionamentos". Além desses autores, Carr et al. (1994) avalia os efeitos das mudanças sobre as pessoas, ênfase nos resultados rápidos, mapeamento dos stakeholders e gerenciamento dos comportamento humano e cultural da mudança. Todas as propostas dos autores citados acima têm como foco adequar as empresas, fazendo com que obtenham uma visão processual e avaliem os impactos das mudanças para com as pessoas, desenvolva treinamento para capacita-las, motiva-las e reduzir resistências à mudança. Segundo Silvia et al. (2009) o gerenciamento de processos precisa ser bem planejado, implementado e monitorado, pois caso não seja, os seus resultados esperados não serão alcançados.

A empresa deverá, ao decidir o tipo de mudança que irá utilizar ter consciência de todos os contextos e da situação que a organização está passando, pois uma vez iniciada e colocada em prática, a empresa deve se ajustar e monitorar continuamente seus resultados (CHIAVENATO, 1996).

Fazendo assim que sua eficácia tenha correlação direta com como as mudanças são implementadas e a eliminação das resistências. A tabela 1 demonstra a comparação entre os autores das metodologias de implementação do gerenciamento de processos e se atendem totalmente, parcialmente ou não atendem aos critérios facilitadores de mudança. 
Tabela 1 - Análise Comparativa entre as proposta de Gerenciamento de Processos com os Critérios Facilitadores de Mudança

\begin{tabular}{|c|c|c|c|c|c|c|c|}
\hline $\begin{array}{l}\text { Autores de Gerenciamento } \\
\text { fe Pritérios } \\
\text { facilitadores } \\
\text { de Mudança }\end{array}$ & $\begin{array}{l}\text { Adair e } \\
\text { Murray } \\
(1996)\end{array}$ & $\begin{array}{c}\text { Carr et } \\
\text { al. } \\
\text { (1994) }\end{array}$ & $\begin{array}{l}\text { Ballé } \\
(1997)\end{array}$ & $\begin{array}{l}\text { Rummler } \\
\text { e Brache } \\
\text { (1994) }\end{array}$ & $\begin{array}{c}\text { Harrington } \\
\text { (1993) }\end{array}$ & $\begin{array}{l}\text { Almeida } \\
\text { (1993) }\end{array}$ & $\begin{array}{c}\text { MCG } \\
\text { Qualidade } \\
\text { (1999) }\end{array}$ \\
\hline Contextualização & $\mathbf{A P}$ & NA & NA & NA & $\mathbf{N A}$ & $\mathbf{N A}$ & $\mathbf{N A}$ \\
\hline $\begin{array}{l}\text { Realização correta do } \\
\text { diagnóstico }\end{array}$ & AT & NA & NA & NA & NA & NA & NA \\
\hline $\begin{array}{l}\text { Gerenciamento da cultura } \\
\text { organizacional }\end{array}$ & NA & AT & NA & NA & NA & NA & NA \\
\hline $\begin{array}{l}\text { Estabelecimento da visão } \\
\text { organizacional }\end{array}$ & AT & AT & NA & $\mathbf{A P}$ & NA & $\mathbf{A P}$ & NA \\
\hline $\begin{array}{l}\text { Identificação e } \\
\text { comprometimento dos grupos de } \\
\text { interesse (stakeholders) }\end{array}$ & $\mathbf{A P}$ & $\mathbf{A P}$ & $\mathbf{A P}$ & $\mathbf{A P}$ & $\mathbf{A P}$ & $\mathbf{A P}$ & $\mathbf{A P}$ \\
\hline $\begin{array}{l}\text { Compreensão e redução das } \\
\text { resistências à mudança }\end{array}$ & $\mathbf{A P}$ & $\mathbf{A P}$ & $\mathbf{A P}$ & $\mathbf{A P}$ & AT & $\mathbf{A P}$ & $\mathbf{A P}$ \\
\hline$\checkmark$ Comunicação & AT & AT & NA & $\mathbf{N A}$ & AT & NA & NA \\
\hline$\checkmark$ Treinamento & AT & AT & NA & AT & AT & AT & AT \\
\hline$\checkmark$ Recompensa & $\mathbf{N A}$ & AT & NA & AT & AT & $\mathbf{N A}$ & $\mathbf{N A}$ \\
\hline$\checkmark$ Benchmarking & AT & NA & NA & NA & AT & AT & NA \\
\hline $\begin{array}{l}\text { Desenvolvimento do plano de } \\
\text { ação }\end{array}$ & AT & AT & AT & AT & AT & AT & AT \\
\hline $\begin{array}{l}\text { Gerenciamento através das } \\
\text { fronteiras internas } \\
\text { (Horizontalização) }\end{array}$ & AT & $\mathbf{A P}$ & $\mathbf{A P}$ & AT & AT & AT & NA \\
\hline Gerenciamento da transição & $\mathbf{N A}$ & NA & NA & NA & NA & NA & NA \\
\hline $\begin{array}{l}\text { Avaliação dos efeitos da } \\
\text { mudança para as pessoas }\end{array}$ & NA & AT & NA & $\mathbf{N A}$ & NA & NA & NA \\
\hline Empowerment & AT & AT & AT & AT & AT & AT & AT \\
\hline $\begin{array}{l}\text { Medição para avaliação e } \\
\text { controle da iniciativa de } \\
\text { mudança }\end{array}$ & AT & AT & AT & $\mathbf{A T}$ & AT & AT & AT \\
\hline Criação de resultados rápidos & NA & AT & NA & NA & NA & NA & $\mathbf{N A}$ \\
\hline
\end{tabular}

Legenda: $\mathrm{AT}=$ Atende Totalmente $\quad \mathrm{AP}=$ Atende parcialmente $\quad$ NA = Não Atende

Fonte: Silvia et at. (2009)

Segundo o estudo de Silvia et al. (2009) as metodologias citadas pelos autores acima demonstram carência dos critérios facilitadores de mudança, colocando a eficácia da implementação do gerenciamento de processos em risco. No caso da empresa analisada, existe uma forte cultura organizacional e existem alguns critérios facilitadores de mudança sendo utilizados, porém somente alguns não garantem o resultado esperado. Assim sendo, os autores do estudo propuseram um modelo com 13 etapas, incluindo os critérios facilitadores de mudança, para implementar o gerenciamento de processos dentro das organizações. Esta pesquisa enriquece a atual pesquisa conseguindo identificar se existem ou não os critérios facilitadores na empresa analisada. 


\section{Métodos e procedimentos de coleta e de análise de dados do estudo}

\subsection{Etapas de coleta de dados}

O presente estudo foi conduzido para identificar e sugerir melhorias processuais ao processo fabril de uma empresa privada do ramo farmacêutico, mais especificamente o segmento de saúde animal. Para isso, foi preciso entender, primeiro, o conceito de processo e suas ramificações. Após isso, demonstrou-se necessário o aprofundamento nas questões relacionadas a gerenciamento da qualidade total, melhorias contínuas, reengenharia de processos, modelagem de processos e gerenciamento de processo.

Desta forma, a natureza deste estudo é qualitativa. Segundo Vergara (2009), existem dois tipos de critérios de qualificação para uma pesquisa, sendo eles: quantos aos fins e quantos aos meios.

Quanto aos fins, a pesquisa é descritiva, pois tendo em vista que o processo foi desenhado para obter a análise da rotina e identificação dos pontos críticos.

Quanto aos meios, a pesquisa é um estudo de caso de uma rotina de atividades pertencentes a uma organização do setor farmacêutico.

\subsection{Fontes de informação selecionadas para coleta de dados no estudo}

O estudo contou com dados secundários oriundos de artigos acadêmicos, dissertações e artigo de revista. Essas bases de dados foram pesquisa obtidas a partir de fontes como BPM CBOK, Revista de Administração de Empresas (RAE), dentre outras fontes.

Outro método utilizado para coletar dados foi o uso de entrevistas individuais com os atores do processo, contando com o auxílio de um roteiro semiestruturado. Todos os entrevistados são atores do processo fabril, tendo como relevância a escolha de um representante de cada departamento, para que desta maneira os dados colhidos sejam o mais heterodoxo possível. 


\subsection{Procedimentos e instrumentos de coleta de dados utilizados no estudo}

Para a coleta dos dados para a utilização no presente estudo, foram utilizadas entrevistas semiestruturadas com cada responsável dos diferentes setores envolvidos no processo. As entrevistas foram realizadas 07 a 09 de novembro e tiveram duração de 15 minutos em média, mas alguns entrevistados usaram mais tempo para expor seu ponto de vista. Os entrevistados se expressaram sobre o seu entendimento; onde identificam os possíveis gargalos no processo; como recebem e gostariam de receber as informações provenientes de seus fornecedores de informação. Além disso, com o fluxograma do processo os entrevistados foram convidados a darem sua opinião sobre o mapeamento e como o modelo, impresso, Ihes ajudavam a entendê-lo melhor e também foram desafiados a propor melhorias ao atual processo As

próprias entrevistas também foram fontes de informações úteis para a atualização do mapeamento do processo, pois serviam para modificar etapas nas quais as atividades eram realizadas. Desta maneira, um modelo atual e finalizado é apresentado na Figura 1.

Como mencionado, foi utilizado um roteiro base. De acordo com Yin (2015), perguntas que se iniciam com "como" e "por que" são mais apropriadas para este tipo de estudo, pois buscam entender as relações casuais do fenômeno exploratório estudado. Desta forma, os atores do processo foram convidados a responder as seguintes perguntas:

1. O que você entende como processo?

2. Qual parte do processo você acha que seria o principal gargalo produtivo?

3. Você imaginaria que o processo seria tão complexo como está apresentado? Se não, como você imaginaria? Te ajuda a enxergar o processo desta maneira? (Entrega do Mapeamento Impresso)

4. Como você gostaria de receber a informação vinda do seu fornecedor (do processo), como eles poderiam te ajudar a executar sua tarefa da melhor maneira?

5. Quais melhorias você daria ao atual processo? Utilizaria melhorias contínuas ou redesenharia alguma processo?

6. Como você considera sua participação ao processo? 
Além das entrevistas, conversas informais com os colaboradores da empresa foram fontes ricas de informações para a realização da pesquisa.

\subsection{Formas de tratamento e análise dos dados coletados para o estudo}

O presente estudo teve com o resultado dos conceitos e informações colhidas para avaliar o processo fabril. Com isso, a análise dos dados colhidos tem como objetivo identificar brechas na realização das tarefas cotidianas organizacionais e propor melhorias. Assim, as entrevistas, uma vez transcritas, foram analisadas minuciosamente para que desta forma conseguissem alcançar os objetivos principais e intermediários. A análise, que foi obtida a partir da coleta das entrevistas, foi comparada com o referencial teórico, o que permitiu categorizar a análise. As categorias ajudaram a apontar melhorias a serem sugeridas à empresa estudada.

\subsection{Limitações do Estudo}

Apesar do método escolhido ser o mais pertinente, percebeu-se duas limitações para o presente estudo. Primeiramente, um dos fatores limitantes do estudo seria a o fato das pessoas institivamente não divulgarem algumas informações por receio de se prejudicarem ou uma terceira pessoa, desta forma, fazendo com que as respostas e ações dos entrevistados ocultassem alguma outra informação. Por fim, é relevante dizer que o autor do presente estudo está inserido no atual contexto estudado e sua visão pode tender a algum viés não percebido, porém todos seus pontos de vista estarão no presente trabalho. 


\section{Apresentação e análise dos resultados}

\subsection{A Empresa}

A empresa estudada é uma multinacional de capital aberto, tendo suas ações comercializadas nas bolsas de valores. Dentro desta multinacional existem três tipos de negócios sendo eles saúde humana, defensivos agrícolas e saúde animal. Em 2010, algumas linhas produtivas, de um desses segmentos de negócios, foram obrigadas, por determinação do seu órgão regulador, que deveriam ser separadas e tratadas de maneira diferente das demais linhas produtivas que existiam dentro desta fábrica. Assim sendo, foi necessário à independência dessas linhas e então surgiu esta empresa, tendo seu negócio de maneira independente, porém se reportando ao seu antigo núcleo de negócio.

Ao longo da separação houve momentos difíceis, passando por auditorias internas e externas, tendo como enfoque a qualidade da produção e na integridade dos processos e informações que é um dos princípios mais importantes e que a organização preza muito. Com a transição, o que se percebe é que muitos processos foram herdados, assim como máquinas e equipamentos, o que, durante muitos anos impossibilitou a empresa de impor suas necessidades.

Embora a empresa não tenha começado do zero, mas sim com uma herança de equipamentos, máquinas e processos, ela precisa agora se adequar às novas diretrizes e procedimentos globais e também ser inspecionada por seus órgãos reguladores, a fim de estar em compliance com todos seus procedimentos, documentações e processos.

Atualmente a organização atua globalmente, com seus portfolio de produtos, sendo eles os mais diversificados possíveis, minimizando os riscos do mercado. A empresa, que atua no segmento de saúde animal, tem ao total onze linhas de produtivas, que juntos atendem ao mercado nacional e internacional (América latina e central).

A Empresa é divida em seis departamentos (Produção, Qualidade, Controle de Qualidade, Engenharia e Manutenção, Supply Chain e Excelência Operacional), ou seja, todas as áreas com atividades relacionadas diretamente ao core business estão situadas no mesmo complexo industrial na cidade do Rio 
de Janeiro, a fim de facilitar a troca de informações e o processo como um todo. As atividades secundárias se encontram nos escritórios da cidade de São Paulo.

\subsection{Descrição do perfil dos entrevistados}

Os entrevistados foram os responsáveis de cada setor envolvido diretamente ao processo e contribuindo diretamente com a realização das tarefas. Suas funções no processo e identificação estão apresentadas na tabela 2 abaixo:

Tabela 2 - Perfil dos Entrevistados

\begin{tabular}{|c|c|c|c|}
\hline Identificação & Função & $\begin{array}{c}\text { Tempo de } \\
\text { Empresa } \\
\text { (anos) }\end{array}$ & $\begin{array}{c}\text { Tempo no } \\
\text { Processo } \\
\text { (anos) }\end{array}$ \\
\hline Qualidade & Analista Sr. & 3,5 & 3,5 \\
\hline Supply Chain (SCM) & Analista PI. & 30 & 2 \\
\hline $\begin{array}{c}\text { Controle de } \\
\text { Qualidade }\end{array}$ & $\begin{array}{c}\text { Supervisor } \\
\text { CQ }\end{array}$ & 13 & 2 \\
\hline Produção & $\begin{array}{c}\text { Supervisor } \\
\text { Fabril }\end{array}$ & 18 & 5 \\
\hline $\begin{array}{c}\text { Excelência } \\
\text { Operacional }\end{array}$ & Analista PI. & 29 & 6 \\
\hline
\end{tabular}

Vale ressaltar que o autor desta pesquisa trabalha no processo estudado, o que viabilizou o acesso ás pessoas e às informações necessárias para a elaboração do presente estudo.

\subsection{Descrição e análise dos resultados}

\subsubsection{Mapeamento do processo}

Com base nos conhecimentos processuais da empresa e também com auxílio dos colaboradores envolvidos no processo, o pesquisador realizou um mapeamento do processo fabril. Fora utilizado o sistema Bizagi para a elaboração do fluxograma, no qual os envolvidos no processo foram convidados a expressar seus conhecimentos de suas funções, desta forma validando o mapeamento. Importante ressaltar que, para a elaboração do mapeamento do processo, foi desenhado o modelo de produção por batelada (conforme 
demanda) e não por campanha (produção contínua), tendo apenas o término do processo como alteração. O modelo também permitiu que os colaboradores visualizassem como, de fato, funciona o processo como um todo. A Figura 1 representa o atual ciclo do processo.

\section{Figura 1 - Mapa do Processo Fabril}

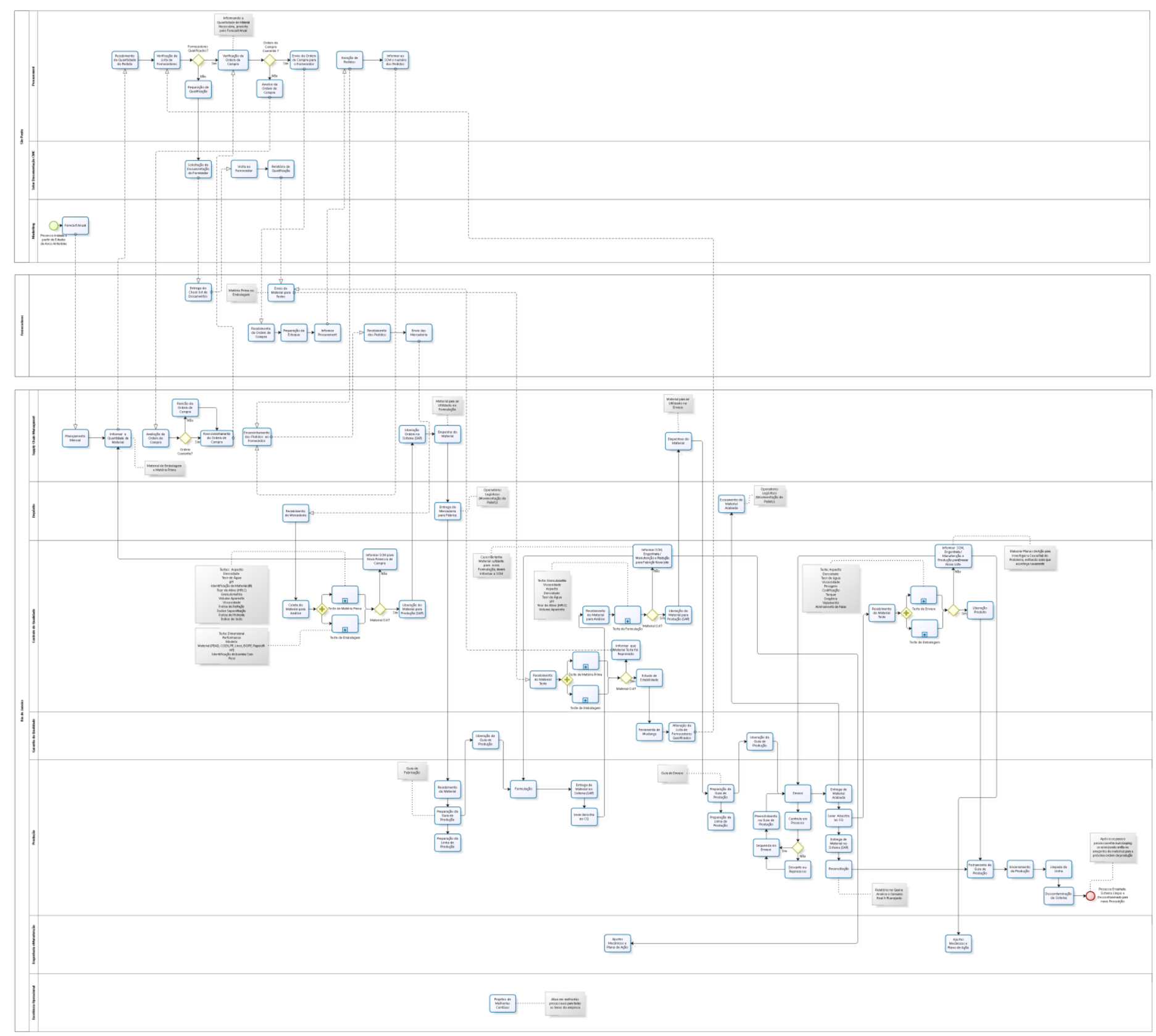

Fonte: Elaboração própria, 2016.

Este Fluxograma representa o fluxo de informações e tarefas relacionadas ao processo fabril da organização estudada. Tendo em mente que um processo é a maneira de como se produz algum bem ou serviço (MALONE et al., 1997), 
tendo como característica a passagem do fluxo de informação/tarefa por diferentes áreas da empresa (interfuncionalidade) (GONÇALVES, 2000).

Foi criado este diagrama (Figura 1), no qual demonstra as atividades realizadas pela organização que ao final do ciclo do processo tem a produção de um bem que agregará valor ao seu cliente.

O processo se inicia com a área de Marketing elaborando o Forecast Anual, com as informações retroativas da demanda que servirá para a área de SCM saber qual a necessidade que a produção terá para atender ao mercado. Uma vez recebido o Forecast Anual, o departamento de SCM elabora o Planejamento Mensal no qual nada mais é do que o desmembramento do Forecast Anual em doze meses. Elaborado o Planejamento Mensal, o SCM informará ao setor de Procurement a quantidade de material necessária para atender ao plano de produção. Após informar ao Procurement, o setor receberá a quantidade do pedido.

Depois do recebimento do pedido a área verificará se o fornecedor é qualificado ou não, caso ele não seja qualificado será requisitado ao setor de Documentação CMC uma série de documentações, check lists e materiais para testes do Fornecedor não qualificado. Após o envio do material teste, o setor de Controle de Qualidade receberá o material e aplicará três estudos (Embalagem, Matéria Prima e Estabilidade), se os testes falharem o Controle de Qualidade informará ao fornecedor e solicitará uma nova remessa de material para testes. Caso os três estudos estejam aprovados o setor da Garantia da Qualidade alterará a Lista de Fornecedores Qualificados através de um software de gerenciamento de mudanças.

Com a lista de Fornecedores Qualificados Atualizada, o setor de Procurement verifica a ordem de compra, se não estiver coerente avalia a ordem e reencaminha ao $S C M$, onde também fará uma análise da Ordem e depois reencaminhará ao Procurement, que por sua vez, envia a Ordem de compras ao Fornecedor. Feito isso o Fornecedor receberá a ordem de compra, preparando assim o estoque e após o preparo informará ao Procurement. Recebida a informação, o Procurement gerará um pedido e informar ao SCM o número dos pedidos, que por sua vez irá encaminhar os pedidos ao fornecedor conforme sua necessidade. O Fornecedor então, de acordo com os pedidos enviará o material para a empresa, desta forma finalizando a primeira etapa do processo, as compras.

Com o processo de compras concluído, o material, proveniente do fornecedor, chegará à organização e será alocado em seu depósito. Com o 
material armazenado, o Controle de Qualidade coletará o material e fará dois tipos de testes, teste de matéria prima e de embalagem, caso os testes falhem o Controle de Qualidade informará ao SCM para gerar uma nova remessa de compra e seguindo assim o processo de compras citado acima, porém se os dois testes forem aprovados o material será liberado para a produção.

Uma vez liberado, o departamento de SCM liberará a ordem no sistema e empenhará o material. Uma vez empenhado o Material, operadores logísticos irão movimentar o material do depósito até a unidade fabril. Após receber o material vindo do depósito, o setor de Produção prepara a guia de produção (Formulação) e prepara a linha pra começar a formulação.

Com a guia preparada, a Produção entrega ao setor de Garantia da Qualidade a guia de produção para ser liberada, uma vez liberada a guia de produção retorna à Produção dando início assim a Formulação. Concluído o processo de formulação, o setor de Produção faz a entrega do material no sistema e leva amostras da formulação para o Controle de Qualidade, que por sua vez recebe o material e dá início ao teste de formulação. Caso o teste falhe, - Controle de Qualidade informa ao SCM e a Produção de que necessita formular novamente e avisa também a Engenharia e Manutenção, que por sua vez elabora um Plano de Ação para evitar que esse defeito venha a se repetir, além de executar ajustes mecânicos (caso necessário). Se os testes forem aprovados o material é liberado no sistema. Uma vez liberado, o SCM empenha este material que será utilizado pela Produção, material já formulado. Assim que o material for empenhado, o setor de Produção prepara a guia de produção (guia de envase) e também prepara a linha de produção.

Com a guia preparada, a Produção entrega ao setor da Garantia da Qualidade a guia de produção para ser liberada, uma vez liberada a guia de produção segue para a Produção dando início assim ao Envase. Durante o Envase ocorre o controle em processos, onde, dependendo do produto envasado, será coletado diferentes quantidades de amostras ao longo do processo de envase.

Com o envase concluído o setor de Produção entrega o material acabado ao depósito, através da movimentação de pallets feita pelos operadores logísticos. O setor de Produção leva a amostra para o Controle de Qualidade aonde são realizados mais dois testes, o teste de envase e o teste de embalagem. Caso os testes falhem o Controle de Qualidade informa ao SCM e a Produção de que necessita envasar novamente e avisa também a Engenharia e Manutenção, que por sua vez elabora um Plano de Ação para evitar que esse 
defeito venha a se repetir, além de executar ajustes mecânicos (caso necessário). Se os testes forem aprovados o Controle de Qualidade libera o produto. O Setor de Produção entrega o material envasado no sistema e faz a reconciliação.

Após essas atividades, a Produção fecha a guia de produção, encerra a produção, limpa a linha e descontamina o sistema para uma nova partida. Ao longo do processo, o departamento de Excelência Operacional elabora projetos de melhoria contínua, alavancando os indicadores de performance da unidade fabril. Desta forma, finalizando a segunda etapa do processo, a produção.

\subsubsection{Variáveis intervenientes}

As entrevistas com cada departamento foi essencial para validar o mapeamento do processo além de auxiliar na elaboração do mesmo. Para a entrevista, foram selecionadas colaboradores chaves dos departamentos chaves para averiguar se todos tinham consciência de um processo, restrições do processo produtivo, processo fabril e a comunicação com os seus fornecedores, melhorias processuais e por fim, como cada departamento considera sua participação no processo.

\subsubsection{Consciência do processo}

O primeiro fator que foi analisado foi saber como cada departamento iria definir processo e saber, tentar perceber se, havia uma unificação de teoria ou se cada departamento iria explicar o termo respaldado de suas atividades. Tendo em mente que a empresa no qual este trabalho está focado é do setor fabril farmacêutico, a palavra processo tende a se referir por um conjunto de etapas, ou atividades, que somadas geram um produto ou serviço para um cliente. Desta forma, o entrevistado era convidado a responder a pergunta: "O que você entende como processo, o que vem à sua mente?". As respostas dadas pelos entrevistados confirmaram que, de fato, eles sabiam o significado do termo "processos", correlacionando sempre com suas respectivas áreas, voltadas ao âmbito operacional. O responsável pela área de Excelência Operacional respondeu:

"Eu entendo que o processo seriam todas as etapas que combinadas fazem com que a gente fabrique um produto. No nosso caso seria desde a parte de recebimento da matéria prima, pelo operador logístico, até a etapa de entrega do produto final. " 
Outra resposta também fez a correlação do termo processo para com sua área de atuação. Um dos Chefes das Unidades Fabris respondeu da seguinte forma:

"Acredito que seja a execução de tarefas a serem desenvolvidas por um grupo de colaboradores ou funcionários de uma organização, sendo toda a parte do nosso processo produtivo. Desde a hora que recebemos a matéria prima, passando pela formulação e envasando o material acabado. "

Outros representantes, de áreas não operacionais, tiveram visões mais amplas do termo e não só se restringindo a uma etapa do processo (a sua), mas sim ao processo fabril como um todo. O responsável pelo Controle de Qualidade, Supply Chain e a representante pela Qualidade responderam, respectivamente:

"É um conjunto de etapas que visa concluir uma tarefa que precisa ser feita em várias partes. Algumas partes desse do processo ocorrendo simultaneamente inclusive."

"Conjunto de medidas, ações contínuas, padronizadas e controladas para atingir um determinado objetivo."

"Etapas ordenadas e parametrizadas que levam a um resultado conhecido e bem definido, produto ou serviço. "

\subsubsection{Restrições do processo produtivo}

Após a pergunta introdutória, era perguntada a cada departamento "Qual parte do processo você acha que seria o principal gargalo produtivo? ", visto que já possuíam um domínio processual e dominavam o processo ou parte do processo. O responsável pela Excelência Operacional, o Chefe de uma das Unidades Fabris e a representante da Qualidade responderam, respectivamente:

"Eu acho que o gargalo sempre vai existir, pois conforme for melhorando a eficiência da linha o gargalo também vai mudando de lugar. Atualmente o principal gargalo se encontra na produção, devido à etapa de fabricação do material avulso utilizados na fabricação do produto final. "

"São quaisquer pontos no sistema que limitam a produção como: falta de matéria prima ou embalagem, burocracia, preenchimento de relatórios, documentos em excesso, e falta de recurso de mão de obra. Sendo assim, acredito que nosso principal gargalo seja na produção. " 
'Pessoas... (cultura de resistência ao processo burocrático, documentação de etapas, necessidade de rastreabilidade, etc). A Qualidade, enquanto setor de interface tende a ter seu gargalo no gerenciamento de pessoas, pois seu processo não consiste em um fluxo unidirecional, pois depende de consolidar os resultados dos processos de todas as áreas envolvidas na cadeia produtiva."

Ambos os departamentos voltados à área operacional visualizaram a Produção como o principal gargalo no sistema, enquanto a Qualidade identificou que as pessoas, sendo resistentes á documentação e somado com a "dependência" de cada setor, fazem com que as próprias pessoas sejam o gargalo, do ponto de vista da Qualidade, identificado com a restrição não física (Marques e Sales Cia, 1998). Interessantemente, o responsável de Supply Chain correlacionou o gargalo, mediante seu ponto de vista, de Produção com a demanda anual de produção (Forecast Anual - Marketing), respondendo da seguinte forma:

"Equacionar a capacidade instalada da planta, falhas e quebras de equipamentos X Forecast, previsão de vendas, de um determinado período. "

Já o responsável pelo Controle de Qualidade teve uma visão ampla do processo, no qual se precisou entender do processo como um todo para identificar assim os pontos de restrições (STEIN, R.E., 1996), respondendo da seguinte forma:

"Depende do ponto de vista do processo: O Controle de Qualidade é um gargalo direto para a produção, porém Procurement é um gargalo para o Controle de Qualidade e provavelmente Previsão de Vendas é um gargalo para Procurement."

\subsubsection{Processo fabril e comunicação com o seu fornecedor}

Durante esta etapa da entrevista era apresentado aos entrevistados o mapeamento do processo para ajudar-Ihes a melhor visualizarem e validarem o modelo. Quando os representantes dos departamentos foram questionados com a pergunta "Você imaginaria que o processo seria tão complexo como está apresentado? Se não, como você imaginaria? Te ajuda a enxergar o processo desta maneira? ", o responsável pela Excelência Operacional e um dos Chefes dos Chefes das Unidades Fabris respondeu, respectivamente: 
"Não, eu achava que seria mais simples. Não tinha a percepção de ser tão complexo. Até porque quando a gente atua em algum projeto para deixa-lo mais eficiente é algo mais focado num setor e não em todas as áreas juntas. "

"Não, pois atuando na área de produção, no chão de fábrica, as atividades dos outros setores já chegam de forma mais clara e restando assim, a gente cumprir a execução das nossas atividades."

Interessantemente, ambas as áreas voltaram a ter a mesma linha de raciocínio, pois como estão sempre muito envolvidos com suas atividades operacionais, não se depararam com a complexidade do processo, somente com a complexidade de suas atividades. Porém, quando as áreas de Supply Chain, Qualidade e Controle de Qualidade foram perguntados todas demonstraram conhecimento da complexidade do processo, pois estão diariamente envolvidas com as várias interfaces do processo, assim, elas responderam, respectivamente:

"Sim, Sob a forma de fluxograma fica ainda mais claro o entendimento do processo como um todo, inclusive para os módulos de interfaces. "

"Sim, já imaginava o processo sendo complexo e a forma como foi apresentada ajuda a confirmar visualmente a complexidade."

"Sim, uma empresa como a nossa que atende ao volume de produção e ao mercado, com toda a carga legal que - mercado exige, precisa compartimentar muito 0 seu processo, tornando-o muito complexo. "

Após essa pergunta, foi perguntado aos entrevistados "Como você gostaria de receber a informação vinda do seu fornecedor de informações, como eles poderiam te ajudar a executar sua tarefa da melhor maneira? ". Ambos os setores de Qualidade e Excelência Operacional, tiveram entendimentos parecidos ao responderem esta pergunta, identificando um ruído no fluxo de informações, fazendo com que a informação não chegue on-time ou até mesmo que tenha uma informação desfragmentada. Assim sendo, o responsável de Excelência Operacional e a representante da Qualidade responderam, respectivamente:

"Fornecendo as informações no prazo, de acordo com diretrizes e procedimentos, avaliando criticamente o que está sendo fornecido. Hoje as informações são recebidas de forma fragmentada, adicionando retrabalho ao meu processo atual, pois é preciso retrabalhar a informação antes de consolidá-la. " 
"Como necessito de informações das áreas para ajudar em projetos de melhorias, creio que melhorar a comunicação entre as áreas e reportando o problema que o processo fabril está passando seria essencial. Como falei, acho que melhorar o canal de informação ou até mesmo repassar a informação $A S A P$, já ajudaria bastante. "

As demais áreas (Supply Chain, Controle de Qualidade e Produção) tiveram um consenso em relação à sua resposta. Como por exemplo, o SCM assinalou que as informações poderiam chegar de modo mais eficiente, oriundas do Marketing, de maneira que não impacte na produção e também na liberação dos produtos e materiais produzidos/envasados a fim de atender as demandas do mercado. Desta forma, os representantes dos departamentos de Supply Chain, Controle de Qualidade e Produção responderam, respectivamente:

"A forma com a qual a informação é recebida, já é bastante adequada a necessidade do trabalho, e uma maneira bem eficaz para a melhoria da execução da tarefa de planejamento seria realizando breefings semanais com os highlights dos maiores desvios de forecast por item. "

"Com um alinhamento mais preciso das etapas que dependem do Controle de Qualidade para o atendimento de suas demandas."

"Gostaria de receber do "Supply" informações mais precisas para evitar o retrabalho e também que os planejamentos mensais, seguidos do plano de produção, sejam realizados por campanha e não por batelada."

\subsubsection{Melhorias processuais}

Nesta parte da entrevista os entrevistados eram perguntados "Quais melhorias você daria ao atual processo? Utilizaria melhorias contínuas ou redesenharia algum processo?". De maneira unanime todos os departamentos afirmaram que a metodologia de melhoria contínua seria a melhor maneira para implementar, fazendo com que as mudanças no âmbito organizacional sejam implementadas, tendo seus colaboradores realizando suas atividades de maneira mais eficiente a cada dia (CHIAVENATO, 2003). Assim sendo, os representantes do Controle de Qualidade, Supply Chain e Qualidade responderam, respectivamente: 
"Continuaria com o uso de melhorias contínuas. Acredito que o redesenho de um processo na atual estrutura, que tem tão pouca margem para erros, representaria um grande risco para o atingimento das metas e continuidade das operações. "

"Acabamos de implementar uma melhoria da qual havíamos identificado, que é o ranqueamento das coberturas de demanda por material, ajudando a definir muito melhor uma sequência de produção de forma que utilizamos um mínimo de esforço para atingir um máximo de performance. Não há necessidade de redesenhar 0 processo, e as melhorias contínuas já são comuns nas nossas práticas. "

"Utilizaria melhorias contínuas por que isso faz parte de uma cultura organizacional. Porém se a melhoria contínua não surte resultados, é necessário avaliar a possibilidade de se redesenhar o processo."

Embora todos os departamentos tenham concordado com a utilização da melhoria contínua, foi percebido que, no ponto de vista do setor da Excelência Operacional, Produção e Qualidade, a cultura da empresa tende a seguir mais a metodologia da melhoria contínua uma vez que "O redesenho radical dos processos de trabalho para atingir uma melhoria dramática no desempenho" (HAMMER E CHAMPY, 1993, p. 37), interpretando que a empresa não tem o perfil de trabalhar com essa característica. Finalizando, os representantes da Excelência Operacional e Produção responderam, respectivamente:

\footnotetext{
"Atualmente utilizamos a metodologia de melhorias continuas, sempre reavaliando o processo e estudando os gargalos de forma a reduzi-los. Acho que redesenhar os nossos processos atuais, seria muito... agressivo e acho que a nossa empresa não tem essa atual postura. A menos que tenhamos, num futuro, um processo novo que apresente " $n$ " gargalos e que a metodologia da melhoria contínua não seja suficiente, ai sim, teríamos que redesenhar o processo. "
}

"Utilizaria o processo de melhoria contínua, porque os nossos atuais processos já são muito complexos e acho que redesenha-los iriam mexer demais com nossa atual estrutura fabril. Atualmente já temos alguns projetos ao longo do ano que visam à melhoria contínua das nossas linhas. "

\subsubsection{Participação processual}

Ao final da entrevista foi perguntado aos entrevistados "Como você considera sua participação ao processo? ". Os departamentos, Produção, Qualidade, Controle de Qualidade e Excelência Operacional tiveram reações similares, ao descrevem suas funções e exaltando sua importância, demonstrando como os departamentos visualizam, ou dão um maior enfoque a 
sua "fatia " do processo produtivo. Segundo Pritchard e Armistead (1999), a abordagem funcional das empresas é baseada em cada departamento executando sua tarefa isoladamente, e desta forma a empresa, como um todo, perde agilidade em seu processo e competitividade no seu segmento de mercado, aonde ocorrem variações rápidas e a constante necessidade de adaptação, demonstrando assim que necessita uma interação mais profunda entre essas interfaces. Sendo assim, o representante de Produção, Qualidade, Controle de Qualidade e Excelência Operacional responderam, respectivamente:

"Como produção desencadeio uma função primordial garantido a execução do programa de produção através de monitoramento, análises, confiabilidade das máquinas, equipamentos e garantindo que nada falte ao processo produtivo e participando de reuniões a fim de discutir um plano de ação para corrigir possíveis desvios."

"A Qualidade garante que o processo esteja em conformidade com normas e diretrizes internas e externas, de forma a evitar problemas com consumidores e órgãos reguladores."

"Importante, podendo contribuir com melhorias de performance e experiência e inclusive impactar negativamente com alguma ocorrência que afete compliance por falha ou omissão em algum processo."

"Acho que minha participação no processo é fazer com que o processo flua da melhor maneira possível e sempre buscando melhora-lo. "

Enquanto os departamentos, Produção, Qualidade, Controle de Qualidade e Excelência Operacional, focaram mais em suas etapas e sua importância para com o processo, o departamento de Supply Chain deu ênfase no processo como um todo, se considerando apenas um elemento de um grande e complexo sistema de engrenagens, no qual parando uma parte, todas param. Assim sendo, foi percebido também que, ao longo das entrevistas, a existência de indicadores de performance eram utilizados pela empresa, porém apenas medindo seus indicadores organizacionais e não setoriais, como por exemplo: service level, documentação errada e demanda produtiva. Desta forma, o representante de Supply Chain respondeu:

"No processo como um todo, me considero apenas um dente da engrenagem, e tenho como responsabilidade fazer com que todas as partes envolvidas no processo tenha essa mentalidade de unidade e cooperação mútua." 


\section{Conclusões e recomendações para novos estudos}

O objetivo principal do presente estudo foi analisar o processo fabril de uma empresa do ramo farmacêutico, mais especificamente do segmento de saúde animal com o intuito de identificar os pontos críticos e sugerir sugestões para o processo como um todo. Para que esse objetivo fosse cumprido, foi necessário apresentar conceitos sobre os processos organizacionais, gargalos, melhorias contínuas, reengenharia e gerenciamento de processos. Desta forma, podendo sugerir modificações para melhorar o ciclo do processo como um todo, dando melhorias técnicas e de gestão.

Com o mapeamento do processo elaborado e as entrevistas, foi possível observar que existe uma etapa do processo que gera lentidão a uma determinada etapa produtiva, a liberação da guia de produção. O setor da Qualidade necessita liberar a guia de fabricação/envase para que o setor da Produção comece a produzir. A demanda dessa liberação é dada pela quantidade de produtos que serão formulados ou envasados, de acordo com o planejamento mensal. A liberação atualmente ocorre de acordo com a ordem de produção, ou seja, uma guia de produção liberada por vez. Neste cenário a liberação pode atrasar a produção caso o colaborador da Qualidade não libere a guia imediatamente após o término de uma produção para dá início ao um novo processo produtivo. Desta maneira, uma possível melhoria nessa parte do processo seria se, de acordo com o planejamento mensal, as guias de produção, tanto de formulação como as de envase, sejam liberadas de uma só vez e entregues à Produção, agilizando assim o processo.

Além dessa oportunidade de melhoria, foi observado que durante as entrevistas, o SCM utiliza as informações provenientes do Forecast Anual, oriundas do setor de Marketing, para elaborar seu plano de produção mensal. Este estudo é baseado em anos anteriores e, ao menos que tenha alguma oportunidade de negócio no qual force a fábrica a produzir algo fora do esperado, existe uma linearidade na demanda anual (estipulando a taxa esperada de crescimento do mercado).

O que se percebeu foi que, a fim de maximizar a produtividade das linhas produtivas e consequentemente das unidades fabris, o setor de SCM poderia 
propor ao setor de Marketing a opção de elaborar produções por campanhas, ou seja, produzir vários lotes de um mesmo produto, minimizando assim o tempo de troca de formato, limpeza nas linhas e descontaminação do sistema, deixando de ter a produção por demanda e passando a ter sua produção por campanhas. Porém para essa melhoria somente será considerada válida se houver um estudo pelo setor de SCM, Produção e Excelência Operacional a fim de provar que o stocklist dos produtos não chegue num nível crítico.

Por meio de entrevistas também foi possível identificar os pontos críticos que não eram possíveis de serem identificados no mapeamento inicial. $O$ primeiro ponto crítico assinalado foi a consciência do processo. Com o mapeamento impresso foi possível demonstrar aos responsáveis das áreas envolvidas o processo como um todo, e consequentemente, alguns dos setores demonstraram desconhecerem da complexidade do processo. Assim sendo, quando uma atividade necessita que haja uma troca de informação entre setores, poderá haver uma resistência por parte das pessoas, podendo gerar até um atrito entre os colaboradores. Essa constatação é confirmada pelas entrevistas e pelos fatores críticos assinalados abaixo.

A baixa consciência sobre o processo é causada, em suma, pela dificuldade ou falha na comunicação, fazendo com que as informações passem por ruídos antes de chegarem aos seus receptores. Todos os entrevistados se queixaram sobre a maneira que recebem as informações provenientes dos seus fornecedores e, ao decorrer das entrevistas contaram também que erros são recorrentes ao longo do processo. Foi percebido que o problema não se encontra no processo em si, mas sim no comportamento das pessoas. Também foi percebida que esse problema não era somente uma falha de comunicação, mas que a empresa possui dificuldades em disseminar as informações, gerando assim essa dificuldade. Sendo assim, uma sugestão para esse problema seria treinamentos, por parte do $\mathrm{RH}$ da empresa, sobre disseminação da informação, fazendo com que os gestores repassem as informações de maneira eficiente, sem causar ruídos no canal de comunicação.

Também relacionado ao mapeamento e as entrevistas realizadas, foi identificado que o Controle de Qualidade como um todo é considerado um ponto crítico ao ciclo do processo. Foi identificado que cada analista de laboratório é responsável por executar uma determinada função no setor, o que desenvolve e permite ao indivíduo uma agilidade processual sob a atividade. Porém, de acordo com o mapeamento, é vital que todos os colaboradores deste setor saibam executar todas as atividades demandas pelo processo, possibilitando 
assim a eventual compensação de um colaborador caso venha ocorrer alguma eventualidade com ele.

Para que exista uma gestão de processo, uma conclusão é que se tenham parâmetros de desempenho, podendo comparar a eficiência da etapa do processo. Com base nas entrevistas e conversas realizadas na empresa, foi observado que existe um software que possibilita esta comparação com o que é considerado standard pela empresa. Porém, esse programa não é validado e então não pode ser considerado um indicador confiável. Como sugestão, o programa poderia passar por um processo de validação, tornando o software confiável, a fim de mensurar o real versus ideal.

Desta forma, os resultados obtidos estão convergentes com a teoria apresentada ao decorrer do estudo: observou-se os atores do processo cientes do significado de processo, aplicabilidade da melhoria continua versus reengenharia. Também se identificou que a empresa implementava treinamentos, dava poder de decisão aos seus colaboradores, e empregava indicadores de performance, porém falhava no quesito comunicação. Sugerindo assim que a empresa utilizasse o modelo proposto, oriundo do estudo de Silvia et al. (2009).

\subsection{Sugestões e recomendações para novos estudos}

O presente estudo ficou limitado ao processo fabril, como um todo, da empresa analisada. Durante as entrevistas, foi possível identificar que os depoimentos visavam a melhorias mais técnicas (operacionais), enfoque este que não foi dado ao estudo. Assim, recomenda-se que, futuros trabalhos se desenvolvem, com o mesmo intuito de melhorar o desempenho processual, nas áreas operacionais das linhas produtivas (formulação e envase).

Além disso, durante o trabalho, novos projetos, em relação à otimização das linhas produtivas, estavam sendo estudados e viabilizados. Desta maneira, recomenda-se também que, ao término destes novos projetos um novo mapeamento seja feito para que as novas necessidades da empresa sejam supridas.

Sugere-se também que sejam elaborados novos estudos sejam feitos caso as melhorias sugeridas no presente trabalho sejam aderidas na empresa, desta maneira podendo comparar o antes e o depois da implementação das sugestões. 
Por fim, sugere-se que um novo estudo seja elaborado caso o governo brasileiro imponha medidas públicas, no segmento da empresa analisada, com vistas ao desenvolvimento fabril, pois dessa maneira a empresa deverá continuar se mantendo competitiva reduzindo seus custos e assim mantendo tanto a excelência na qualidade quanto a sua vantagem competitiva. 


\section{Referências Bibliográficas}

ABPMP. Guia para o Gerenciamento de Processo de Negócio Corpo Comum de Conhecimento (BPM CBOK). São Paulo: Elsevier, 2013.

ADAIR, C. B.; MURRAY, B. A. Revolução total dos processos. São Paulo: Nobel, 1996.

AGGARWAL, S. A Quick Guide to Total Quality Management. Business Horizons, Greenwich, v.36, p.66-68, 1993.

ALMEIDA, L. G. Gerência de processo: mais um passo para a excelência. Rio de Janeiro: Qualitymark, 1993.

BALLÉ, Michael. Reorganizando sua empresa: um kit de ação para reengenharia. Rio de Janeiro: Infobook, 1997.

BIAZZO, S., Approaches to business process analysis: a review. Business Process Management Journal, v.6, n.2, p.99-112, 2000.

BRESSAN, C. L. Mudança Organizacional: uma visão gerencial. In: I Seminário de Gestão. Anais Curitiba - FAE, 2004

CARR, D. K. et al. Ponto de ruptura: redesenhando o processo de negócios. Rio de Janeiro: Qualitymark, 1994.

CAULLIRAUX, H., CAMEIRA, R. Consolidação da Visão por Processos na Engenharia de Produção e Possíveis Desdobramentos - Disponível em: <http://www.abepro.org.br/biblioteca/ENEGEP2000 E0113.PDF> Acesso em 07 de novembro de 2016.

CHIAVENATO, I. Introdução à teoria geral da administração. São Paulo: McGraw-Hill do Brasil, 1996.

CHIAVENATO, I. Introdução à Teoria Geral da Administração. 7ª Edição. Rio de Janeiro: Campus, 2003.

CORREIA, K., LEAL, F. ALMEIDA, D. Mapeamento de Processo: Uma Abordagem Para Análise de Processo de Negócio - Disponível em: $<$ http://www.abepro.org.br/biblioteca/ENEGEP2002 TR10 0451.pdf > Acesso em 20 de novembro de 2016. 
DAVENPORT, T., SHORT, J. E. The new industrial engineering: information technology and business process redesign. Sloan Management Review, v. 31, n. 4, 1990.

FISCHI, R.M. Gerenciamento pela Qualidade Total - SISEB. Rio de Janeiro, 3 de maio de 2012. Disponível em: < http://www.aprendersempre.org.br/arqs/APRESENTA\%C7\%C3O sdg gerencia mento qt apresenta\%E7\%E3o-1.pdf > Acesso em 06 de novembro de 2016.

GONÇALVES, J. E. L. As empresas são grandes coleções de processos. RAE: Revista de Administração de Empresas, São Paulo, v. 40, n. 1, p. 6-19, 2000.

GONÇALVES, J. E. L. Processo, que processo?. RAE: Revista de Administração de Empresas, São Paulo, v. 40, n.4, p. 8-19, 2000.

GUERREIRO, R. Os Princípios da Teoria das Restrições Sob a Ótica da Mensuração SciELO Brasil - Caderno de Estudos, 1996 Disponível em: <http://www.scielo.br/pdf/cest/n13/n13a03.pdf> Acesso: 21 de outubro de 2016.

HAMMER, M., CHAMPY, J. Reengenharia: Revolucionando a Empresa em Função dos Clientes, da Concorrência e das Grandes Mudanças da Gerência. Rio de Janeiro: Ed. Campus, 1993.

HAMMER, M., Reengineering Work: Don't Automate, Obliterate.

Harvard Business Review, p 110-2, 1990.

HARRINGTON, H. J. Aperfeiçoando processos empresariais. São Paulo: Makron Books, 1993.

HARRINGTON, H. J. Business process improvement. New York: McGraw Hill, 1991.

KETTINGER, W., TENG, J. T. C., GUHA, S. Business process change: a study of methodologies, techniques, and tools. MIS Quarterly USA, v.21, n. 1, p. 5580, 1997.

LIPNACK, J., STAMPS, J. Virtual teams. New York: Wiley, 1997.

MACIEIRA, A.; JESUS, L. A Evolução do BPM nas Organizações Brasileiras. Bpm em Foco, Edição 1, jan. 2013. Disponível em: < http://www.issuu.com/elo group/docs/revista-em-foco 1?e=10278579/6587406.> Acesso em: 18 de novembro de 2016. 
MALONE, T. et al. Tools for inventing organizations: toward a handbook of organizational processes. Boston: MIT, 1997.

MARQUES, J. A., CIA, J.N. Teoria das Restrições e contabilidade Gerencial: Interligando Contabilidade a Produção. RAE: Revista de Administração de empresas. v.38, n.3, p.35-38, 1993.

MCG Qualidade. Guia para gerência de processos e projetos. São Paulo, 1999.

MICHAELIS. Moderno Dicionário da Língua Portuguesa. Disponível em: $<$ http://michaelis.uol.com.br/busca? $r=0 \& f=0 \& t=0 \&$ palavra=processo $>$. Acesso em: 26 de outubro de 2016.

POLAKOFF, J.C. Computer Integrated Manufacturing: A New Look at Cost Justifications Journal of Accountancy 169.3, March, 1990. Disponível em $<$ http://search.proquest.com/openview/261bf6c3d633d9415bef19f06954c085/1.p $\underline{\mathrm{df} \text { ?pq-origsite }=\text { gscholar } \& \mathrm{cbl}=41065}>$ Acesso em: 26 de outubro de 2016

PORTER, M. Vantagem Competitiva: Criando e Sustentando um Desempenho Superior. Rio de Janeiro: Editora Campus, 1989.

PRITCHARD, J. P.; ARMISTEAD, C. Business process management: lessons from European business. Business Process Management Journal, v. 5, 1999.

RUMMLER, G. A.; BRACHE, A. P. Melhores desempenhos das empresas. São Paulo: Makron Books, 1994.

STEIN, R. E. - Re-Engineering the Manufacturing System - Applying the Theory of Constraints, New York: Marcel Dekker, 1996.

SILVA, S. M. et al. Uma análise crítica do Gerenciamento de Processos com base nos critérios facilitadores de mudança. XXXIII Encontro da ANPAD - São Paulo/19 a 23 de setembro de 2009.

TENDICK, Jeffrey. Managing change or leading change... which way are you going to go? 1999. Disponível em:< www.mattlorenz.com $>$ Acesso em: 21 de outubro de 2016. 
VALENTINA, V. Desenvolvimento de um Modelo Integrado de Reengenharia de Processos com Melhoria Contínua Para o Redesenho de Processos, junho de 1998, disponível em: $<$ https://repositorio.ufsc.br/xmlui/bitstream/handle/123456789/77548/139325.pdf? sequence $=1$ \&isAllowed $=y>$ Acesso em: 31 de outubro de 2016.

VILLELA, Cristiane S. S., Mapeamento de Processos como Ferramenta de Reestruturação e Aprendizado Organizacional. Dissertação de Mestrado pelo Programa de Pós-Graduação em Engenharia de Produção, Universidade Federal de Santa Catarina, Florianópolis, 2000.

WELLINGTON, P. Estratégias Kaizen para Atendimento ao Cliente, São Paulo: Educator, 1999. 


\section{Anexo 1}

\section{Mapa do Processo}

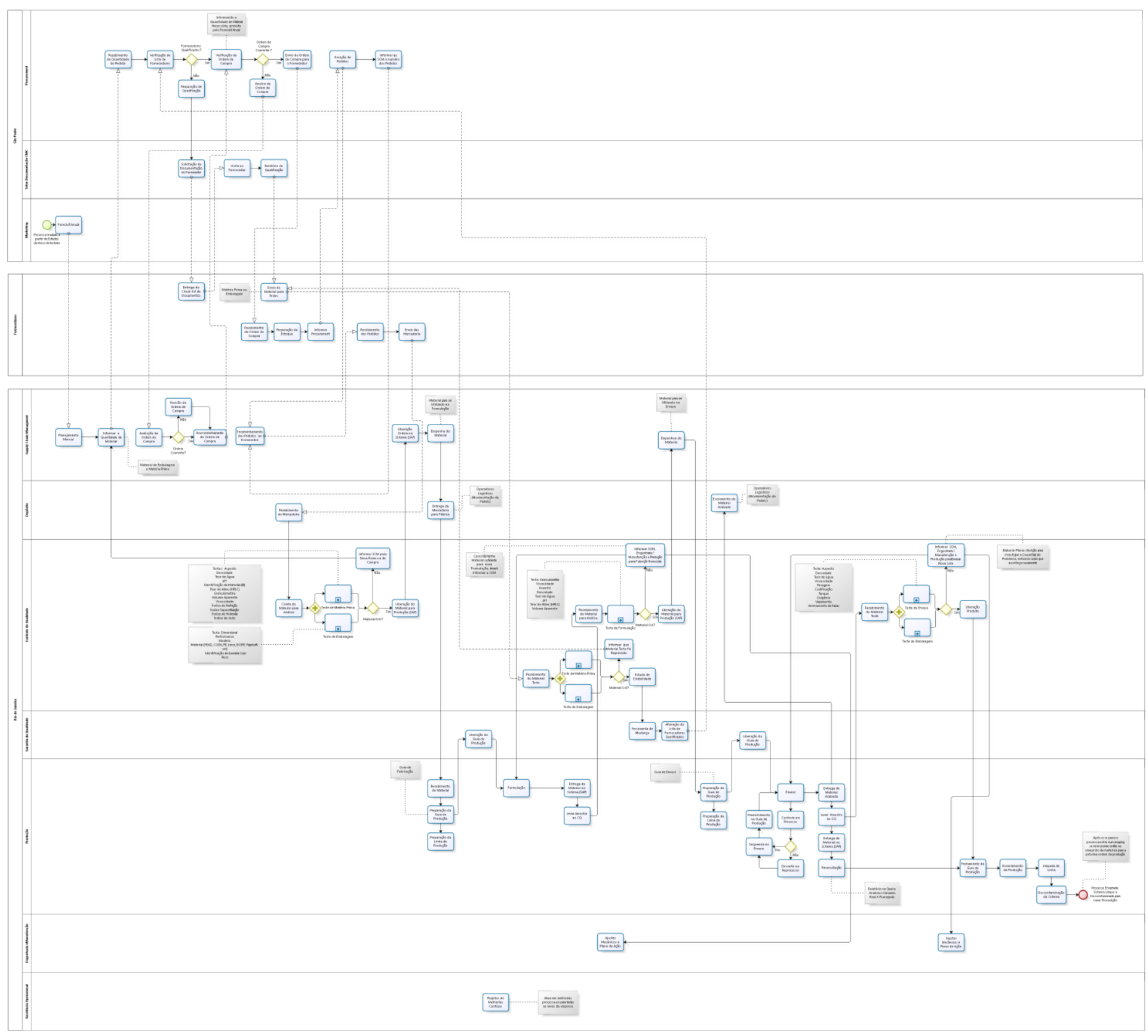

